\title{
SOS ThelTLAS
}

\section{The Aesthetic Experience of Time, in between the Hourglass and the Self}

\author{
Hans Dieleman ${ }^{1}$, Francesca Cozzolino ${ }^{2}$, and Anne Bationo ${ }^{3},{ }^{1}$ Autonomous University of Mexico City \\ (UACM), Email:hansdieleman@gmail.com; ${ }^{2}$ Ecole nationale superieure des Arts Decoratifs (EnsAD), \\ Email:francesca.cozzolino@ensad.fr; ${ }^{3}$ C3U/Paragraphe/ UniversiteParis 8, Email: annebationo@hotmail.com
}

Received 25 December, 2017; Revised 15 January, 2018; 22 January 2018

Copyright (C)2017 Hans Dieleman, Francesca Cozzolino and Anne Bationo. This is an open access article distributed under the Creative Commons Attribution License (https://creativecommons.org/licenses/by/4.0/), which permits unrestricted use, distribution, and reproduction in any medium, provided the original work is properly cited.

Available online 22 January 2018 at www.atlas-journal.org, doi: 10.22545/2017/00095

\section{particul}

his article interrogates time and presents the results of an ethnographic study in a railway station in the suburbs of Paris. More in particular, it analyses the interactions of some of the passengers with 'Texel', an experimental artistic dispositive composed of a number of hourglasses that responds to the movements of the passengers. The study identifies several processes and conditions that explain why some passengers did interact with Texel, while others did not. Subsequently, it explores aesthetic experiences realized during the interaction of people with the device. It focuses on the passage from "aesthetics of perception" to "aesthetics of operation", and on interactive works of art creating such aesthetics. It observes that this takes place in spaces in between the internal experience of the passenger and the external reality of the artistic device, and that this aesthetics is transdisciplinary as it integrates cognition, emotions and enacting. Finally, the article explores some links between aesthetic experience and transdisciplinary hermeneutics, and between intermediary spaces of experience and Nicolescu's concept of the Third Included.

Keywords: Interactive art, aesthetic experience, transdisciplinary hermeneutics, time, intermediary space of experience, third included.

\section{Introduction}

Time is an objective phenomenon. It can be measured in quantitative units like hours, minutes, seconds, years or decades. Our clocks tick at the same speed everywhere on the planet and because of that, time exists outside, and independent from us. Yet time is also a subjective experience. As the expression "time flies when you are having fun" indicates, our experience of time is contextual. When we have fun, times goes fast, when we have to wait, it goes slow. It is not at all objective, but precisely very subjective. Time can also be measured, or experienced, in terms of events, or periods, before, during and after. It is the experience of time, and time 
itself, that is central in this text.

We are interested in experiencing time and more in particular, and the concept of aesthetic experience, which we see as a conscious experience, full of significance. Aesthetic experiences have transformative potential as they have the power to redefine our understanding of the world, truth, relevance, or simply: reality. We want to explore if aesthetic experiences also have the power to change our understanding of time, and we are interested in the role of art in provoking such aesthetic experiences and new understanding. We will introduce "Texel", an artistic and experimental dispositive produced by the French Forum Vies Mobiles, ${ }^{1}$ and designed by Lyes Hammadouche and Ianis Lallemand, within EnsadLab, the research laboratory of the French National School of Decorative Arts in Paris. ${ }^{2}$ Texel was realized as an installation in the Ermont-Eaubonne railway station in the residential area of the Val d'Oise, in the suburbs of Paris, in the period of November 16 to December 16, 2015.

We present the results of an ethnographic study carried out by Anne Bationo, Francesca Cozzolino and Clara Lamireau-Meyer. Anne, Francesca and Clara studied the interactions between the passengers of the train station and Texel, during the period mentioned. They wanted to know if Texel changed the passengers relationship with time and under what conditions such changed occurred. They identified several processes and conditions, such as singularization, the change from time as a flow to floating time, taking an active stand vis-à-vis Texel and estrangement or defamiliarization $[1,2]$. We explore the links that exist between the concepts of aesthetic experience and transdisciplinary hermeneutics, and conclude that aesthetic experiences are essentially transdisciplinary. We observe that an essential element in both is that they work with a space in between, combining emotions with cognition allowing us to have conscious experiences, full of significance. We also identify some areas where one concept can learn from the other.

\footnotetext{
${ }^{1}$ www.forumviesmobiles.org

${ }^{2}$ http://www.ensadlab.fr/fr/forum-vie-mobile/
}

\section{Texel, a Work of Art That Interrogates Time}

The art installation "Texel" interrogates time. The work is composed of a number of interactive hourglasses, conceived in a modular logic. Each module consists of an hourglass of approximately forty centimeters long, placed in a Plexiglas frame with two metal arms, a motor and a sensor (see Figure 1). Each module reacts to the movements of the public. By default, the hourglasses are held in a horizontal position, preventing the flow of sand. When a person comes close enough to an hourglass, the hourglass moves slightly, rotating a few degrees forward or backward, starting the movement of the sand. If the traveler moves away from the module, the hourglass returns to its horizontal position, stopping the movement of the sand. But if, intrigued, he or she advances towards the module, the hourglass continues its rotation, bowing all the more as the spectator approaches him. The device combines automatism, mechanics and sensors, and relies on an allegory: the flow of sand represents the course of time.

The creators of Texel were interested in particular aspects of time, notably time and movement, and time and place or, in other words, in the complex "time-place-movement", present in specific ways in a railway station. This constitutes a double relationship, that of Texel influencing the experience of time-place-movement in the railway station, and that of the railway station influencing the experience of time-place-movement vis-à-vis Texel. It is this triangle of the artwork, its public and the physical environment in which experiences take place that was interesting the creators of Texel, and the researchers investigating the interaction of the public with Texel. A poster, placed above the installation on top of the artistic credits, accompanied Texel:

"Time has replaced distance as the stan-
dard of displacement. It is timed with ex-
treme precision and often experienced as a
time-out rather than full and subjectively
appreciated. The interactive installation
Texel questions these perceptions of time
and travel in the station."

Texel fits into several artistic traditions, like an epistemological tradition in which artists made time the object of various proposals, criticizing in particular the determinism of temporality. As Elie 

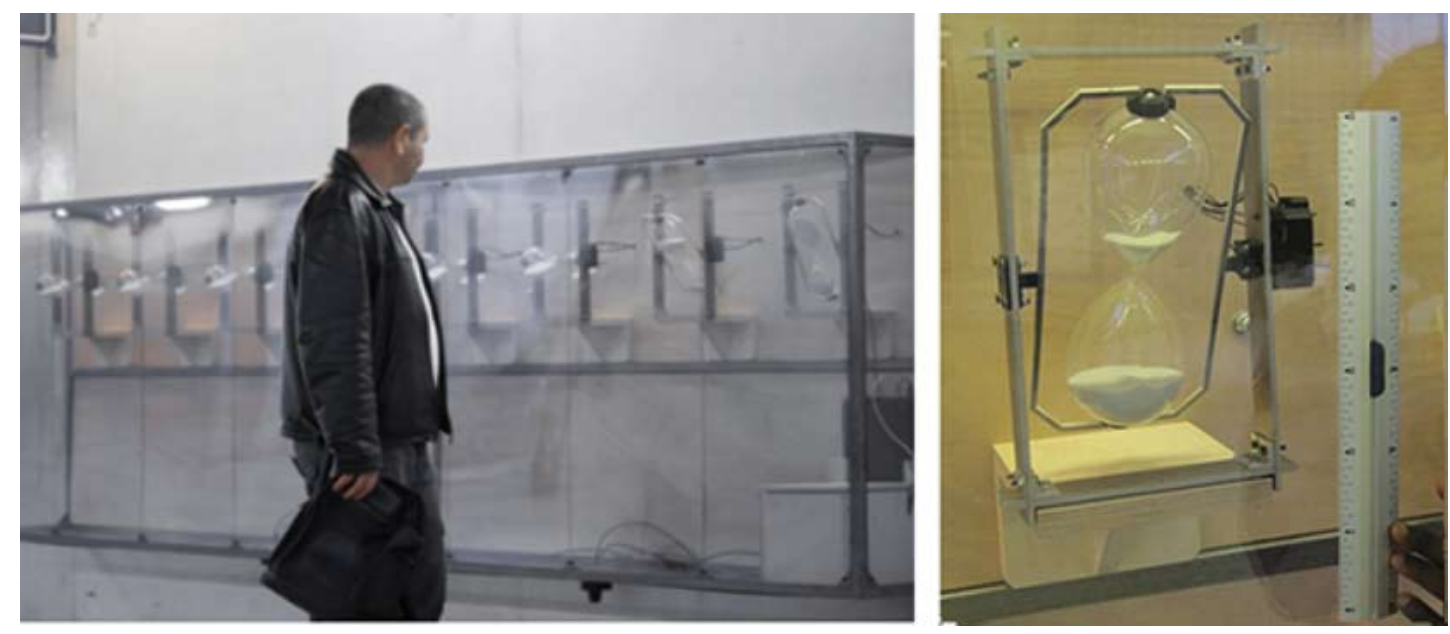

Figure 1: Texel, with passenger and detail of one hourglass (Source: Bationo, Cozzolino and Lamireau-Meyer, 2016).

During shows in his book "False Connections, the co-existence of images" 3 [3], many of these artistic projects give shape to particular experiences of time, questioning determinism and linearity. This ranges from videos that play with the expansion of time, made possible by the use of slow motion (like those of Bill Viola or Michel Snow), up to locative media, who question the idea of the omnipresence of ubiquitous and pervasive computing systems. Instead, they focus on the production of localized interfaces that are functionally bound to a particular locations or space-time.

Texel above all fits into the tradition of interactive art, based on the notion of interface, relationship and inter-action [4]. As such, Texel is representative of the research carried out in EnsadLab, and especially the group working on Reflective Interaction. ${ }^{4}$ It can be seen as a paradigm of contemporary art that proposes to rethink the role of interaction in aesthetic experience. It focuses on an extension of such experience, from an experience merely based on visual perception towards an experience routed in action and interaction. In other words, it explores the passage from "aesthetics of perception" to "aesthetics of operation". Participation is no longer thought of as simply activating dynamic devices but assumes true social value. The beholder of the work of art is not only part of the work's environment, but is a true participant in action $[5,6,7,8,9]$.

In this paradigm, artists create artistic devices or

\footnotetext{
${ }^{3}$ The correct title is: Faux raccords. La coexistence des images. The book is not available in English

${ }^{4} \mathrm{http}: / /$ diip.ensadlab.fr/en/
}

dispositives that rely above all on strategies to capture, model, or even program behavior and integrate them into objects, to foster aesthetic experience, rather than to perform a technical function. In the case of Texel, interaction is not a form of manipulation to make the work "operative", as switching a button on or off; it rather is a condition to make the work act, as in inter-act. The interaction is mutual. Texel makes the passer-by "act", and not only in an instrumental way. Texel modifies the trajectory of displacement of the passers-by, who in turn make the hourglasses act. Interaction must be understood here as the operative relationship between people and things, between people and people, between things and things. In this, it is the work of art that places the viewer in the position of a practitioner; that is to say, he or she is not in a contemplative posture but part of a particular arrangement of agency [10].

\section{Mass, Flow, Time, Movement, Place, Slowdown and Opening}

In their ethnographic study, Bationo, Cozzolino and Lamireau-Meyer explored various aspects of this particular arrangement of agency created by Texel, as well as of the complex "time-place-movement", within the railway station of Ermont-Eaubonne. They observed the movement of the passengers on different moments, like on peak hours during weekdays, outside peak hours and during weekends, and were particularly interested in the interactions of the 


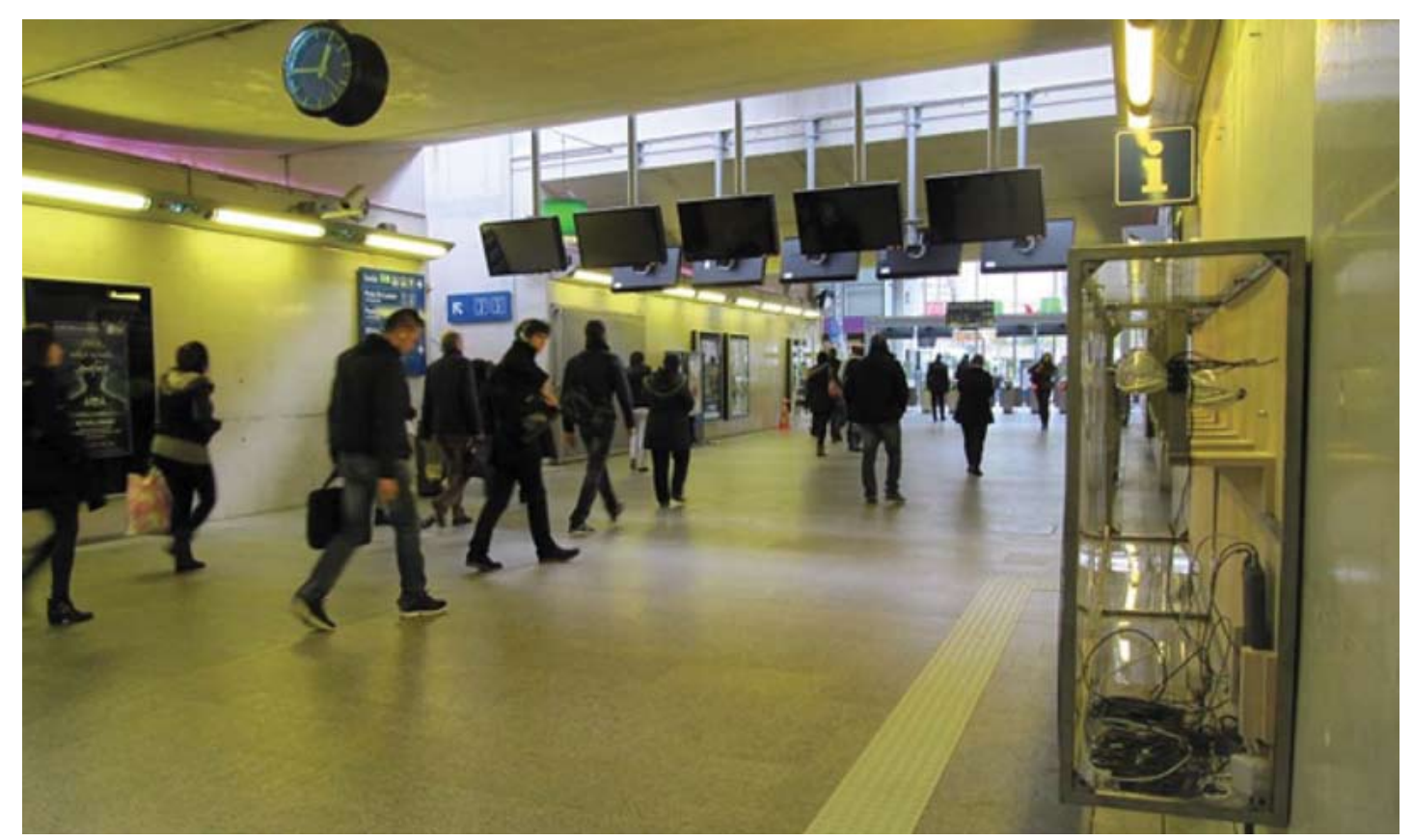

Figure 2: People passing by without seeing Texel (Source: Bationo, Cozzolino and LamireauMeyer, 2016).

passengers with Texel. During the period of Texel's exhibition at the station, from 16 November to 16 December 2015, they conducted observations and interviews during 20 half days, switching between what they called a psycho-phenomenological and an ecological perspective. Within the ecological perspective, they studied the movements of the passengers as a group, and the relations between all the variables in the station, like the people, their movements and particular objects within the station. This was done especially to study the working of the artistic device in the particular context of a station. Within the psycho-phenomenological perspective, they studied the experiences of passengers in relation to Texel.

The researchers observed first of all that the station as a whole functions like a dispositive, in which people act in particular ways to realize certain patterns of, particularly, time, space and movement. They observed clear synchronizations between the rhythm of the passengers and the rhythm of the station. During the weekdays and in the rush hours, the population is predominantly between the ages of 16 and 50. The ebb and flow of users of the station is at a very steady pace: every 10 seconds the flow is reversed. The users move in a sustained cadence forming a compact mass, creating a general pattern of ebb and flow: a small herd arrives at the top; the most athletic ones are engaged in a sprint. Then groups of dozens of passengers follow, moving at a race pace as well. Subsequently, there are a few clusters of less hurried people, like "a young woman and her bike" "a man with a backpack" "three women chatting" [11]. At the end of each very dense group, one or two people come running very quickly from the entrance of the station, trying not to miss the train. $90 \%$ of the users use the corridor without stopping while looking at the timetable / platform and train displays installed in the passage (see Figure 2).

In this way, the Ermont-Eaubonne station processes on average 35,000 passengers per day, passengers who are usually rushing without being open to see and experience anything outside of their main orientation to catch a train. In this group or configuration, it could be said that passengers are already connected to the productive world of work before they even arrive at the workplace. The interviews carried out confirmed this view. Like the 50-year-old lady who mentioned that she passes here every day but that "usually she does not pay attention" or the man telling "I have never seen the installation Texel because I run too fast to catch the train like everyone else" [12].

The passengers join a mass engaged in racing, they "de-singularize" to join a flow that pours all to their workplaces. This de-singularization goes hand in hand with a wider environmental impermeability, 
with a focus narrowing down on time-flow-movement that constrains the passengers, leaving no room for the unexpected, or for reflection. Very much as Ulrich Beck described, reflection has made way for reflex [13]. People act in reflexes, without thinking, without reflection. In the station, this is very much interlinked with another phenomenon. The passengers form part of a flow, which has relevance in two ways. First it means becoming part of a group, a mass, and secondly it means being part of a movement, a moving mass. What the researchers noticed during their study is, that becoming attentive the Texel (and eventually engaging in aesthetic experience) required both a movement of re-singularization, as well as a movement of slowdown. To switch from reflex to reflection to aesthetic experience seems to imply a movement towards becoming a singular individual again, who "has" time and is not "running out of" time.

Out of peak hours, the situation changes considerably, as is to be expected. Passengers arrive by cluster in much quieter ways than earlier in the morning. The range of ages is widening, with older people entering, visibly retired. People cross the corridor quietly. Some stop in the hall just before the corridor in order to watch the station display, or to wait for companions. Flow gradually converts in floating, and more precisely in floating time [14], because people have time to wait for a train, and their journey is an activity of predilection (the church, an exhibition, a walk, a restaurant with relatives...), which does not fit in the world of productivity. Under these circumstances, they are more open to walk around, make a detour, being attracted by the peculiarities of the environment. Time as a flow of objective units makes way for time as a sequence of events, while the passengers, in a manner of speaking, sail at the whim of the events that arise along the way. Moreover, these passengers, at that moment, are singular beings connected to their universes of predilection, a universe that favors a de-focusing, and allows for a greater porosity with the vagaries, and the unexpected fruits of wandering. They, at that moment, live in a floating space-time, which allows for a personalized intermingling of the rhythm of the singular world and the rhythm of the station. This being in floating space-time facilitated the encounter with Texel.

\section{Aesthetic Experiences and the Intermediate Area of Experience}

What happened, after passengers were individualized and open enough to meet Texel? Could their encounters be characterized or qualified as aesthetic experiences? Before answering these questions, we need to define better what an aesthetic experience is. We look at an aesthetic experience as a conscious experience, realized when someone is fully aware of what is happening at a certain moment. It is not superficial, but by contrast full of significance. It touches upon notions of meanings and values, and has transformative and creative power as it can change certain meanings and values, and can (re)-create notions of truth or of reality [15]. Aesthetic experiences equally are truly transdisciplinary, as they involve (or are the result of) interaction between emotions and cognitive thinking processes. As Nelson Goodman argues, in aesthetic experiences, there is a heightened operation of both cognition and emotion working together, and more in particularly in the words of Goodman, one feels "emotions functioning cognitively" [16]. In terms of the transdisciplinary concept of Basarab Nicolescu, this means that in aesthetic experiences, we perceive the world over various levels of reality through transdisciplinary hermeneutics, integrating emotions, senses, subjective experiences and formal knowledge [17]. This allows us to experience complexity, and to create a fusion between a subjective and objective notion of reality $[18,19]$. Near the end of this arcticle, we will come back to this link with transdisciplinarity.

As Sacha Kagan rightfully argues, aesthetic experiences can arise in everyday life, and not only in the confrontation with works of art. However, he continues, artistic creations are especially conducive to aesthetic experience, as they touch upon senses, cognition and emotions in multifold ways, and deliberately seek reflection [20]. The interesting aspect of Texel is, that it combines the two. It seeks aesthetic experience in daily life, yet provoked by a work of art. What is crucial for us is, that aesthetic experiences have as much to do with the activities of 'observers' as with those of 'creators', or as Goodman expressed this, a work of art is never guaranteed to "work" [21]. This depends on the spectator's abilities and attention, as on the environment and the circumstances for contemplation. For Goodman, art only exists if there is a meeting with 
a visitor able to understand and see. Kagan sees this in a similar way, yet formulates it in slightly different words: "whereas an artist may realize an "art product", it is only through the dialog between the "art product" and the observer that a "work of art" arises"; for to perceive, a beholder must create his own experience" [22]. As mentioned before, in the paradigm of the EnSadLab in Paris, where Texel was designed, the notion of dialogue has been replaced with - or specified towards - that of interactivity and operation. The question if the encounters with Texel led to aesthetic experiences therefore must be answered in particular in terms of the interactions of passengers with Texel vice versa.

This question of interaction was central in the ethnographic study carried out by Bationo, Cozzolino and Lamireau-Meyer. They applied the work of the British pediatrician and psychoanalyst D. W Winnicott, and more in particular his concept of the "intermediary area of experience" [23, 24]. Using this concept opened an interesting way to look at aesthetic experience, and allowed for the comparison with transdisciplinarity, and especially Nicolescu's concept of the "third included", as we will emphasize near the end of this arcticle. Winnicott defines the intermediate area of experience as follows: "In the life of every human being, there is inner reality, an external reality and a third reality, while the in termediate area of experience contributes to shape and reshape simultaneously the experience of the inner and the external life. Thus the intermediate area of experience arises in the interlacing of the worlds: initially between the baby and the mother, then between the child who becomes an adolescent and the family, gradually between the individual and the society. Winnicott emphasizes the importance of objects like dolls that function as intermediates between the "I" and the world in early childhood [25]. It is through such objects that the relationship between the "I" and the "thou" or the "it" is being defined, through experiencing them, interacting with them while attaching symbolic meaning to them (Winnicott speaks of third objects that include also persons). According to Winnicott, we keep exploring and defining reality in between the "I" and "it" throughout life, in intermediate areas of experience using objects, thus exploring and testing various possibilities of seeing and defining reality.

Such experiences are most intense within the realms of the arts, science, religion and imaginative living in general, and Winnicott sees those spaces as places of coming and going where new forms of presence constantly reconfigure themselves to the world and to others. It is therefore fair to say that aesthetic experiences are realized in intermediate areas of experience, which can be characterized as areas of dialogues or interactions between the beholder and the object of beholding. Bationo and Cozzolino [26] studied such areas of intermediate experience, placing them in the context of the characteristics of the station, and the characteristics of the groups of passengers in the station. The first distinction they made was, following the work of [27], distinguishing the passengers in two groups, those who were open and those who were closed to the experience with Texel. As we saw, the majority of the passengers remained closed for the reasons previously outlined. It cannot be said however that all who were open, entered an area of intermediate experience and that those who did, all realized an aesthetic experience. For the last to happen, people need to really enter in a dialogue or an interaction, as a way of engaging in an experiment that opens a space of possibilities.

\section{Defining Texel or Exploring Texel}

When passengers were individualized and open enough to meet Texel, the events that enrolled could indeed be characterized in terms of entering in intermediate areas of experience and aesthetic experience, but this was not true for all. Various configurations could be distinguished. Some took time to look at Texel, defined it in a certain way, and then moved on without interacting. Part of the passengers that approached Texel, defined it in affirmative ways: it is this or that. Some defined Texel at a kinetic level, through its movements, often related to the flow of passengers, the movement of the passing trains, or the time the doors are open. Others made observations like "It's an hourglass, I think connected to the movement of the train, and vehicles that come out of the station" [28]. Sometimes the association was made with other technological devices installed in stations such as sites to recharge mobile phones. In most of these qualifications or definitions, passengers attempted to bring Texel closer to the productive and quantitative logic of the station. Others attached meaning to the movement of hourglasses, making references to television or even the Bible. It reminded some of the hourglasses used in television 
debates, to measure the time between two interlocutors. Another mentioned: "We, all humans, are in the hourglass ... in the Bible there is a passage that compares us to grains of sand" [29].

Characteristic for this configuration is, that the initial openness of the passengers towards Texel was of short duration. The mere act of defining, instead of entering in an experiment to explore, closed the meeting almost immediately. This equally was true for those who defined Texel in a negative way. Like some high school students who, after reading the poster, laughed and said: "this is useless, it is an attraction for the stupid". In a conversation that developed with one of the researchers, they continued making similar remarks: "I do not do not understand the principle, for me it's not art, it's a trap for fools" [30].

Another configuration showed real interest in Texel, without being able to define it, yet didn't reject Texel. Like a mother and her son who were waiting for the bus and took the time to wonder, moved round and laughed at the contact they made with Texel. To the researcher present at that moment, they said "We did not know how it moved, we moved to check it, we saw that it moved in relation to our movement and as soon as we stopped, it flipped back in its original position, as if it calculated the time of the person before it. Or like the engineer, interested in technique. "It interests me, I'm an electrical engineer, it's original but I have no explanation ... I think I'll stop tomorrow or after tomorrow if I'm late again ... I'll try to think for myself what it can be and maybe, later, I will read the poster" [31]. Characteristic for these people is that, even though they are open to exploring the device, they define Texel as a mere external reality, and their definitions do not include themselves or involve their own internal reality. In such cases as well, no intermediary area can be created. This changes when a relational experience with the work is realized.

Intermediate areas are created when a relational experience with the work is realized, and this as well happened in the train station. In a number of cases, passengers were interacting with Texel for up to 80 seconds, walking back and fourth, approaching the installation, moving back again, etc. The researchers measured this, using cameras to record movements of passengers in front of Texel, thus complementing qualitative observations and interviews with quantitative data. In this way, they were able to record discoveries of Texel, in intermediate areas of experience. In these cases, passengers no longer defined Texel as something outside of them, but incorporated in the experience their own life stories, biographical expressions, denunciations of stressful work situations, and memories of the past. Memories provoked by Texel, like those of a couple of elders who talked in the interview about their lived experiences of the stations in the years 1960-1970, or a girl remembering her youth in Africa [32].

Characteristic of these moments is their joyfulness and playfulness. Some started to dance in front of Texel, inviting the installation to be their dance partner, to provoke movement and respond to that movement, as in a real dialogue or dance (see Figure 3). In such moments, Texel no longer described the world (time, the station, etc.) as a constative statement, but functions as a real performative entity, having an impact on the experience of reality at that moment. Participants were no longer occupied by time; they were giving meaning to time, in interaction with Texel, through joint operation. In such moments as well, a genuine area of intermediate experience in between the external and the internal reality emerges. In those intermediate areas of experience, passenger engage simultaneously in various worlds, their actual worlds, worlds of the past, imaginative dialogues/worlds with Texel creating possibilities of new worlds. In such moments, the conditions for aesthetic experience are being fulfilled, and passengers did have such aesthetic experiences. They created and recreated reality; their experience was full of significance and meaning, transforming their memory of the past and their experience of the present.

\section{Floating Time, Interaction and Art as a Device of Defamiliarization}

Time and interaction appear to be crucial in creating conditions for aesthetic experience, while the two are entangled, and the entanglement is deepened by the characteristics of the artistic dispositive Texel. The passengers creating the moving masses are subordinate to time, which they perceive as a perpetual flow. They move in function of time, which is bigger than they are. They not only fear running out of time; they are literary lost in time, as the standard for displacement. Time for them is linear, measurable 


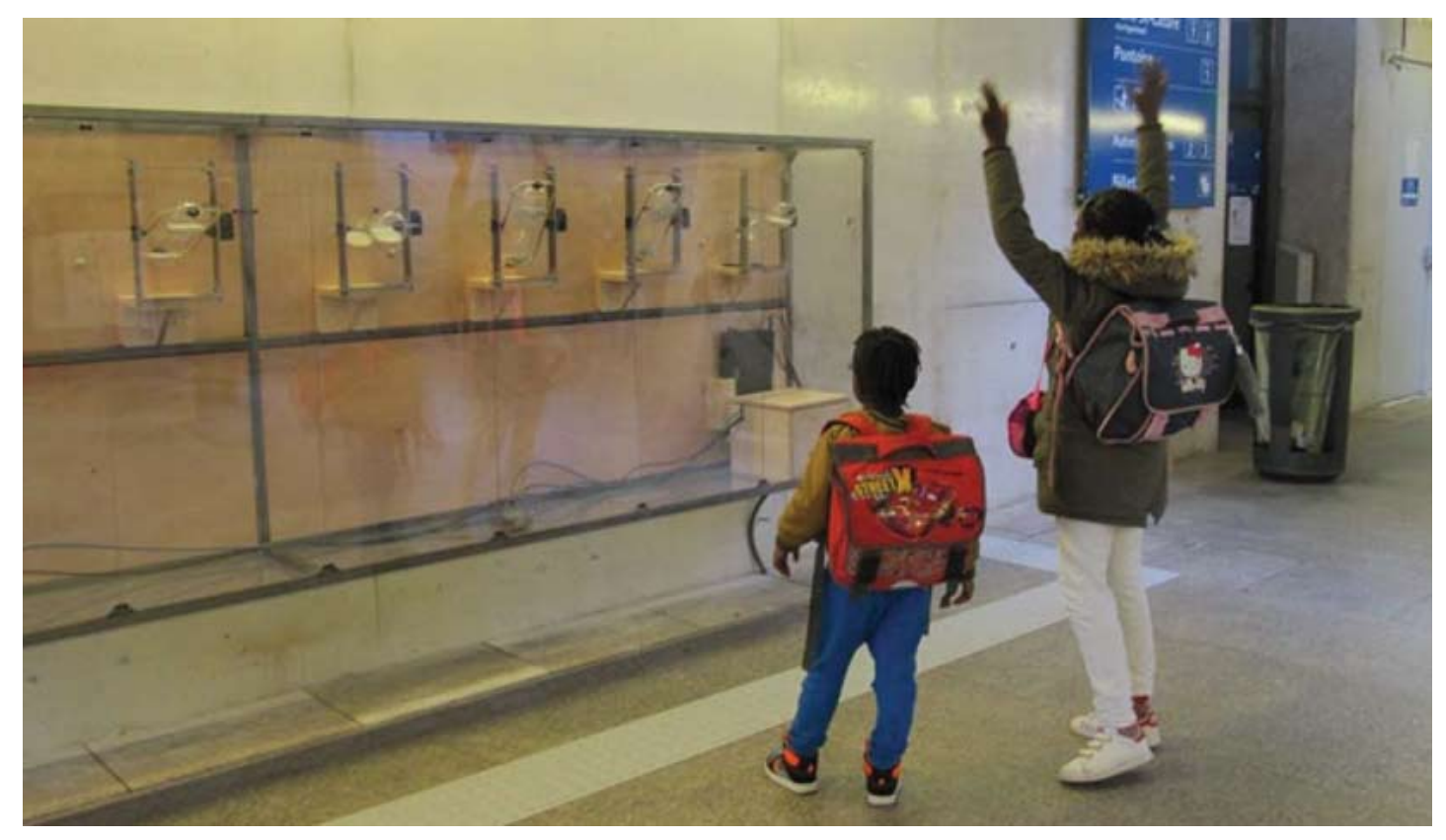

Figure 3: Passenger dancing in front of Texel (Source: Bationo, Cozzolino and Lamireau-Meyer, 2016).

and objective, and they subjectively experience it as something to constantly catch up with, to constantly rally behind. The passengers that experimented with Texel, on the other hand, possessed time and occupied time. They were masters of time, defining it and giving it meaning.

Following the French philosopher Elie During, who coined the concept of floating time, we can also say that they experienced time as a sequence of events with specific durations [33]. They were mastering a "floating time", defined by During as a tangle or a bundle of durations. During sees time as a co-existence of durations with some form of simultaneous disjunction and connection between them. Time is therefore one, yet multiple and complex. Not all events and durations communicate with each other, and neither are they absolutely separate; there are degrees of separation. This complicates the coexistence of events and durations (and time as such), but equally opens up space to escape time. The passengers that form the different configurations previously mentioned, can switch configuration. Those who danced with Texel in one particular moment may, in other moments, by part of the moving mass, vice versa.

This disjunction of time - from acceleration to deceleration to acceleration again, from flow to floating to flow again - was crucial, but what makes people change from one to the other? External time con- straints are obviously very important, and cannot be ignored. In rush hours, most passengers simply don't have time to interact with a work of art. Yet, outside of rush hours, other factors become important. As we saw, those who defined Texel, either in an affirmative, non-affirmative, positive or negative way, quickly lost interest, and their initial curiosity quickly vanished. Those who entered in a relationship of indetermination with respect to Texel however, remained curious. Indetermination therefore can be seen as a second important variable favoring - eventually - aesthetic experience. Not all who were indeterminate however entered in an experiment with Texel, but those who did certainly started from a position of indetermination. Indetermination is a necessary but not a sufficient condition, as it can remain a rather passive state of mind, which is not followed by entering a purposeful experiment, and possibly an aesthetic experience. For this to happen, it is important to take an active stand, which can be a mere mental or cognitive stand, and an embodied stand as in enacting or interacting with the work of art.

Taking an active stand can be seen, following the work of the literary theoretician of the Russian formalist school Viktor Shklovsky, as allowing oneself to enter in a process of defamiliarization or estrangement, of estranging us from what we are accustomed to perceive [34]. It is a process of awakening from the 
usually rather functional way of seeing the world and ourselves, as unfreezing a frozen perception based on the habit of taking the world for granted. Being a theoretician of literature, Shklovsky, emphasizes the importance of language as a way of engaging us in the process of defamiliarization, and distinguishes among artistic language and everyday language. Prose is ordinary speech - economical, easy, functional - which causes an individual to function as though by formula, in an automotive mode. Artistic language, like poetry, is imaginative and imagery and because of that, intensifies and energizes reality, estranging the reader from everyday functionality. Russian formalism saw literature - and eventually all art - as a device applying certain techniques, which embody the capacity to provoke estrangement, including estranging the reader from him or herself.

As a device, Texel indeed "deployed" certain techniques - the hourglasses, the sensors - and functioned outside the mere instrumental, as in poetry instead of prose. The purpose of the creators of Texel was close to that of estrangement, as it invited passengers to take distance, and to defamiliarize from the fixed and frozen way they normally see a station, time, movement and displacement. It explicitly looked for a multiple rupture of frame, one with respect to the station, a second with respect to the time of travel in the station and a third with respect to ones own presence in the station. In order to make this happen, movement and interaction was a requisite.

The interaction with the hourglass was followed by a reinterpretation of the hourglass, and eventually time. This interaction allowed passengers to think of time no longer in mere functional and linear terms, but in terms of events and duration. Even though passengers who engaged in Texel were already in a floating time, this floating times deepened as the result of the interaction with Texel, leading them to rethink themselves, in terms of for instance reviving events of the past. Passengers who really engaged in a relational and operative experience with Texel entered in logic very different from the day-to day functional logic of a station, a logic that can be characterized as imaginary and reflective, creative and joyful.

Crucial was interaction and enacting. The switch from "prose to poetry" only was realized through interaction, dancing with Texel, as a true "aesthetics of operation" instead of "aesthetics of perception". In other words, it was no longer the beholder of the work of art that made art "work", but it was the enactor who made the work of art act, while the work of art simultaneously made the enactor act. It is a joint man-machine enacting within a specific arrangement of agency, with the aim of performativity, creating an aesthetic experience of reality in real time. This depended on a set of particular characteristics, such as those of the public or participants of the artwork (openness, indeterminacy, estrangement), the availability of time (floating time and time as a flow), and the wider context in which the interaction with the artwork was realized (the train station). For art to work, all these variables play a crucial role, in an entangled way. They favor or hamper aesthetic experience, in the case of Texel aesthetic experience of time, in between the hourglass and the self.

\section{The in-between, Aesthetic Experience and Transdisciplinary Hermeneutics}

Aesthetic experiences have many dimensions, characteristics, and conditions to be fulfilled for their deployment, as the experiences with Texel show. One characteristic is their transdisciplinarity, which we want to explore in further detail in this last section of the text. According to Goodman, in aesthetic experiences emotions work cognitively. There is a heightened operation of both cognition and emotion, while we experience them working together. They create a reality that is no longer subjective or objective, emotional or rational, real or perceived, but a reality in which all of these elements and their apparent contradictions exist together and are - somehow - interconnected.

Goodman's notion is in fact very close to Nicolescu's concept of transdisciplinary hermeneutics [35, 36]. Transdisciplinary hermeneutics essentially is a way of integrated and interpretative knowing. It is a process in which we integrate various ways of knowing, more in particular cognitive (conceptual, science-based) knowing with experiential (enacted, practice-based) knowing with embodied (emotional, sensorial, feelings-based) knowing [37, 38, 39]. According to Nicolescu, transdisciplinary hermeneutics enable us to give meaning to life, and allows us to relate with reality not only in mere cognitive and sterile ways, but also in emotional and engaged ways. Moreover, it allows us to see in reality not only that 
what can be perceive in mere sensorial ways, but it equally allows us to see imagined and felt realities, and combine those. Nicolescu questions on a very fundamental level the contradiction that we normally see between reality and fantasy. What we consider to be reality is always an interpretation, in which we use certain ideas, categories or concepts that are not "out there" as such, but that we subscribe to reality. Such interpretations are loaded with that what we assume, imagine, conceptualize or want, and are thus full of "fantasy" as in the Greek word "phantasia", which means "power of imagination, appearance, image or perception" [40]

In aesthetic experience, we experience reality through transdisciplinary hermeneutics. As Goodman mentioned, emotions and cognition work together or, as Nicolescu points out, it allows us to perceive material as well as imagined and felt realities. What we feel and know, imagine and perceive, all interact and creates in interaction an understanding of reality. It provides us with meaning and has transformative potential, as it potentially changes the concept of reality we have.

Comparing aesthetic experience with transdisciplinary hermeneutics makes us also aware of a certain limitation in Goodman's work. Why does he restrict aesthetic experience to emotions and cognition working together? Why does he not include action, enacting and operation? In the concept of transdisciplinary hermeneutics just presented, we distinguished between cognitive, enacted and embodied knowing or, in other words, cognition, emotions and actions. This is not an arbitrary selection, but based on insights of neuroscience. Our brain functions in interaction with our body and integrates what we do, what we feel and sense with our analytical and logical thinking capacities. Body, cognition and action in a particular environment are one [41]. What we can learn from this is that aesthetic experience is a form of experience in which emotions, cognition and action, as a threesome, always work together. Emotions work cognitively vice versa, while acting upon works both emotional and cognitive.

This transdisciplinary deepening of Goodman's notion of aesthetic experience equally provides us with a theoretical base for what we previously called the passage from "aesthetics of perception" to "aesthetics of operation". This concept, currently being developed within the research developed in the group
"Reflective Interaction" at Ensadlab ${ }^{5}$ implies that the beholder of the work of art is not only part of the work's environment, but is a true participant interacting with the work of art. In epistemological terms this means that the work of art is a genuine and important actor in our understanding of reality, and that the work of art is a co-creator of reality, or of our interpretation of what we encounter in the world [42]. As we have seen in the case of Texel, the interaction, as a form of exploration or operation, was a key condition for aesthetic experience to take place. It is therefore fair to extend Goodman's concept of aesthetic experience to cognition, emotion and action working together, as a threesome [43]. This should be seen as an important deepening of Goodman's work on aesthetic experience.

There are more similarities that lead to mutual learning between the concepts of aesthetic experience and transdisciplinary hermeneutics. Transdisciplinary hermeneutics takes place in spaces that Nicolescu calls "third included" or "hidden third" [44]. Transdisciplinary knowing cannot be reduced to the pure subjective and neither to the pure objective; it takes place in a space in between the subjective and the objective, a space where knowing always involves the creation of reality. Nicolescu's concept of the third included has various similarities with Winnicott's concept of the intermediary area of experience, which Winnicott called a third reality that simultaneously shapes the experience of the inner and the external life. So, aesthetic experience, through transdisciplinary hermeneutics, takes place in spaces in between the internal and external experience, or in between the subject and the object of knowing. In this respect, there is an almost one-on-one fusion of the two.

Winnicott's intermediary area of experience has one element though, which is missing in the theory of transdisciplinary hermeneutics, the element of the "third object". We think that the concept of the third object can be a valuable extension to

\footnotetext{
${ }^{5}$ http://diip.ensadlab.fr/en/. See also: Bianchini S. et Verhagen E. (dir.), Practicable. From Participation to Interaction in Contemporay Art, Cambridge - Londres, MIT Press, 2016. Bianchini S.l et al., "(Mis)Behavioral object, empowerment of users vs empowerment of objects", in BIHANIC David (dir.), Empowering Users Through Design, Interdisciplinary Studies and Combined Approaches for Technological Products and Services, Berlin, Éd. Springer, 2015, p.129-152. Bianchini S. et Fourmentreaux J.P., "Médias praticables : l'interactivité à l'uvre", in Sociétés 2007 / 2, no 96, Bruxelles, Éd. De Boeck Université, p. 91-104.
} 
the theory of transdisciplinary hermeneutics, especially third objects as works of art. Nicolescu writes extensively about the importance of art in transdisciplinary hermeneutics, as art works both with what is seen as with what is imagined. In his terminology, art works over various levels of reality and this makes art intrinsically transdisciplinary [45]. Yet, Nicolescu mainly talks about art in abstract terms, instead of art as concrete works of art, as third objects. The introduction of third objects, and especially third objects that work over various levels of reality, like works of art, can help in important ways in making us perceive reality in transdisciplinary hermeneutical ways. The experiences with Texel, as described in this text, show how it was especially the interaction with Texel, as a third object, which made people redefine themselves, their environment and the object they were interacting with. The interaction with third objects, especially works of art, can play important roles in stimulating transdisciplinary hermeneutics, especially when deployed as "aesthetics of operation".

The experiences with Texel in the context of the railway station, yet points at one more "lesson" to take into consideration when thinking of transdisciplinary hermeneutics. Can, or should we always try to understand and know the world in transdisciplinary hermeneutical ways? Are there restrictions and conditions to be fulfilled that allow us to be transdisciplinary hermeneutical? The answer seems to be that there are, and those conditions probably are very similar to the ones previously laid out with respect to aesthetic experience. A big part of our lives, we need to act in rather unconscious ways, and because of that, habits have their valuable function. When we were supposed to reinvent reality every day, and be aware of complexity all the time, there would be little time left to ensure our survival. The experiences with Texel show us that people open up to reflection - as in aesthetic experience and transdisciplinary hermeneutics - once they can afford to do so. Nicolescu mentions that it doesn't make sense, and is even dangerous, to question the objectivity of the world around us all the time, like when we are driving a car in traffic. Yet, as the experience with Texel, it is possible to create "niches of time" within day-to-day life, for reflection, as in aesthetic experience and transdisciplinary hermeneutics. Such niches are very valuable and certainly should be stimulated and advocated.
Finally, we like to point at one last way in which transdisciplinarity can contribute to our understanding of aesthetic experience. Aesthetic experience is not only seen as a conscious and meaningful experience full of significance, but is often seen as well as a way to realize a fusion with the world, enabling us to be "one" with the world in a holistic sense. This way of looking at aesthetic experience has been rather common in the literature, and was particularly strong in the use of art in nature studies and sustainability, stimulated by Suzi Gablik's influential book "The Reenchantment of Art" [46]. Gablik looked at art almost as a tool to re-establish a Romantic fusion with nature, as a countervailing power against de disenchantment of the rationalized world. In his article "The end of aesthetic experience", Shusterman concludes that seeing aesthetic experience as a (romantic) fusion of a person with the surrounding world contributed in considerable extent to the loss of interest in the concept of aesthetic experience. Nowadays, he argues, "it may seem very "retro" to suggest that aesthetic experience can function something like an empathy box" [47]. In an attempt to rescue the concept of aesthetic experience, he emphasizes once more its meaning as" heightened, meaningful, and valuable phenomenological experience" and as a directional concept, "reminding us of what is worth seeking in art and elsewhere in life" [48].

What we want to emphasize, taking transdisciplinarity in consideration, is the following. A fusion with the world, felt in moments of aesthetic experience, does not imply a feeling of wholeness that eliminates contradictions and ambiguity (as in romantic fusion or harmony). On the contrary, it may make us feel and experience wholeness as complexity, acknowledging that the way we know and relate to reality creates multiple understanding of reality. It does not integrate objective and subjective reality, like objective and subjective time, through reducing the one to the other, but makes us experience or know, or become conscious - that both exist at the same time, while neither one can be reduced to the other. It is this complexity that, we like to argue, is worth seeking for in art and elsewhere in life, as a countervailing power against simplicity and one-sidedness, so strongly present in contemporary societies. 


\section{Conclusion}

There is objective time and there is subjective time, as there is an objective and a subjective world, in which we both live. Each have their own logic and in moments of aesthetic experience, through transdisciplinary hermeneutics, we are able to integrate these dimensions and experience complexity. Passengers of the Ermont-Eaubonne railway station, while interacting with Texel, were masters of floating time yet remembered memories of the past, belonging to linear time. Even though the interactions with Texel were events of limited duration, they exceeded that duration as they integrated events of the past. The notions of time as duration and time as a linear flow did not dilute, but went hand-in-hand without any problem. The passengers identified Texel - at first - as a world outside of them, yet created an intermediary reality in between Texel and themselves, which overarched the contradiction of the subjective and the objective, or the internal and the external. Texel became part of them, while they became part of Texel, while neither of them disappeared.

Certain conditions need to be fulfilled, while objects and interaction with those objects seem to be crucial. Works of art, which speak the language of poetry instead of prose, facilitate defamiliarization from everyday reality. Interaction makes works of art act, while those interactions simultaneously make the enactor act. In both aesthetic experience as in transdisciplinary hermeneutics, action and operation is crucial, to realize what we also might call, aesthetics of transdisciplinarity.

Author Contributions: Paper was written collaboratively by the authors.

Funding: This research received no external funding.

Conflicts of Interest: The authors declare no conflict of interest.

\section{References}

[1] Bationo, Anne, Cozzolino, Francesca and LamireauMeyer, Clara (2016). En Quête de temps; questionner le rapport sensible au temps des usagers d'une gare. tude sur l'expérimentation du projet Texel, Présentée par EnsadLab, laboratoire de l'École nationale suprieure des Arts Décoratifs, Paris.

[2] Bationo, Anne and Cozzolino, Francesca (2017). En quête de temps. Quand un dispositif artistique interactif convoque des expriences inédites du temps.
Actes du colloque : Le numérique à l'ére des designs: de l'hypertexte à lhyper-expérience. H2PTM 2017, Hermés, Lavoisier, 2017, p.168-186.

[3] During, Elie (2010). Faux raccords. La coexistence des images. Paris, Actes Sud.

[4] Quinz, Emanuele. (2012). Il cerchio invisibile. Ambienti, sistemi, dispositivi, Milano, Mimesis.

[5] Idem

[6] Bianchini, Samuel and Fourmentreaux, Jean-Paul (2007). Médias praticables: l'interactivité à l'uvre. In: Sociétés 2007 / 2, no 96, Bruxelles, Ed. De Boeck Université, p. 91-104.

[7] Bianchini, Samuel (2012). La performation. Quand faire, cest dire. In: FOURMENTRAUX Jean-Paul (dir.). L'Ére post-média. Arts, Humanités digitales et Cultures numériques. Paris, Éd. Hermann, coll. Cultures numriques, 2012, p. 137-162.

[8] Bianchini, Samuel et al. (2015). (Mis)Behavioral object, empowerment of users vs empowerment of objects. in BIHANIC David (dir.). Empowering Users Through Design, Interdisciplinary Studies and Combined Approaches for Technological Products and Services, Berlin, Ed. Springer, p.129-152

[9] Bianchini, Samuel and Verhagen, Erik (eds.) (2016). Practicable. From Participation to Interaction in Contemporay Art. Cambridge-London, MIT Press.

[10] Gell, Alfred (2009). L'art et ses agents. Une théorie anthropologique, Dijon, Les presses du réel.

[11] Bationo, Anne, Cozzolino, Francesca and LamireauMeyer, Clara (2016). En Quête de temps; questionner le rapport sensible au temps des usagers dune gare. Étude sur l'exprimentation du projet Texel, Présentée par EnsadLab, laboratoire de l'École nationale supérieure des Arts Décoratifs, Paris, page 62.

[12] Idem, page 73.

[13] Beck, Ulrich (1994). The reinvention of politics: towards a theory of reflexive modernisation, in Beck, U., Giddens, A. and Lash, S. (Eds.) Reflexive Modernization. Politics, Tradition and Aesthetics in the Modern Social Order. Stanford University Press.

[14] During, Elie (2010). Faux raccords. La coexistence des images. Paris, Actes Sud.

[15] Dewey, John (1934). Art as Experience. New York: Perigee, 2005 (1934)

[16] Goodman, Nelson (1976). Languages of Art. Hackett Publishing Company, page 248

[17] Nicolescu, Basarab (2010). Methodology of Transdisciplinarity - Levels of reality, Logic of the Included Middle and Complexity. In: Transdisciplinary Journal of Engineering $\& 5$ Science. Volume 1, No. 1, December, 2010, pp.19-38 
[18] Dieleman, Hans (2016). Steps to an Ecology of Knowing and Teaching embodied Transdisciplinary Hermeneutics. Transdisciplinary Journal of Engineering 83 Science ISSN: 1949-0569 online, Article ID 00081, 2016 TheATLAS, Vol. 7, pp. 79-92

[19] Dieleman Hans (2017). Transdisciplinary Hermeneutics: A Symbiosis of Science, Arts, Philosophy, Reflective Practice, and Subjective Experience. In: Issues in Interdisciplinary Studies, An Annual Publication of the Association for Interdisciplinary Studies, AIS, Nr. 35.

[20] Kagan, Sacha (2011). Art and Sustainability - Connecting Patterns for a Culture of Complexity. Transcript Verlag, Bielefeld.

[21] Goodman, Nelson (1976). Languages of Art. Hackett Publishing Company.

[22] Kagan, Sacha (2011). Art and Sustainability - Connecting Patterns for a Culture of Complexity. Transcript Verlag, Bielefeld, page 219.

[23] Winnicott, Donald Woods. (1971). Playing and Reality. Penguin Books.

[24] Winnicott, Donald Woods. (1973), The Child, the Family, and the Outside World, Middlesex Publishers.

[25] Idem.

[26] Bationo, Anne and Cozzolino, Francesca (2017). En quête de temps. Quand un dispositif artistique interactif convoque des expriences inédites du temps. Actes du colloque : Le numérique à l'ére des designs: de l'hypertexte à l'hyper-expérience. H2PTM 2017, Hermès, Lavoisier, 2017, p.168-186.

[27] Pastré, Pierre (2011).La didactique professionnelle. Approche anthropologique du développement des adultes, Paris, PUF, 2011.

[28] Bationo, Anne, Cozzolino, Francesca and LamireauMeyer, Clara (2016). En Quête de temps; questionner le rapport sensible au temps des usagers dune gare. Étude sur l'exprimentation du projet Texel, Présentée par EnsadLab, laboratoire de l'École nationale suprieure des Arts Décoratifs, Paris, Page 94.

[29] Idem, pages 95-96.

[30] Idem, page 81.

[31] Idem, pages 95, 96 .

[32] Idem, page 85

[33] During, Elie (2010). Faux raccords. La coexistence des images. Paris, Actes Sud.

[34] Shklovsky, Victor. ([1917] 20082008). L'art comme procédé, Paris, Allia., [1917] 2008

[35] Nicolescu, Barsab (2002). Manifesto of Transdisciplinarity. Albany: State University of New York Press.
[36] Nicolescu, B. (2015). The Hidden Third and the Multiple Splendor of Being. In: V. Bazhanov and R. W. Scholz (Ed.), Transdisciplinarity in Philosophy and Science: Approaches, Problems, Prospects. Navigator, Moscow, 2015.

[37] Dieleman, Hans (2015). Transdisciplinary Hermeneutics; Working From the Inner Self, Creating Ecologies of Knowing. Transdisciplinary Journal of Engineering \& Science, December, Vol. 6, pp.7285.

[38] Dieleman, Hans (2017). Transdisciplinary Hermeneutics: A Symbiosis of Science, Arts, Philosophy, Reflective Practice, and Subjective Experience. In: Issues in Interdisciplinary Studies, An Annual Publication of the Association for Interdisciplinary Studies, AIS, Nr. 35.

[39] Dieleman, Hans (2012). Transdisciplinary artful doing in spaces of experimentation and imagination. Transdisciplinary Journal of Engineering \& Science, Vol 3, December 2012, pp. 44-57.

[40] The American Heritage (2013). Roget's Thesaurus. Houghton Mifflin Harcourt Publishing Company.

[41] Kiverstein, Julian \& Miller, Mark (2015). The embodied brain: towards a radical embodied cognitive neuroscience. Frontiers in Human Neuroscience.

[42] Vermersch, Pierre (1994). L'entretien d'explicitation. Issy Les Moulineaux, ESF.

[43] Ingold, Tim (2013). Making: anthropology, archaeology, art and architecture, London, Routledge.

[44] Nicolescu, B. (2010). Methodology of Transdisciplinarity - Levels of reality, Logic of the Included Middle and Complexity. In: Transdisciplinary Journal of Engineering \& Science, Volume 1, No. 1, December, 2010, pp.19-38

[45] Nicolescu Basarab (2012). Transdisciplinarity: the hidden third, between the subject and the object, in: Human 85 Social Studies. Research and Practice. Volume 1, Issue 1, Pages 1328, November 2012

[46] Gablik, Suzi (1992). The reechantment of art. London: Thames and Hudson.

[47] Shusterman, Richard (1997). The End of Aesthetic Experience. The Journal of Aesthetics and Art Criticism, Vol. 55, No. 1. (Winter, 1997), pp. 29-41, page 39

[48] Idem, pages 39-40. 


\section{About the Authors}

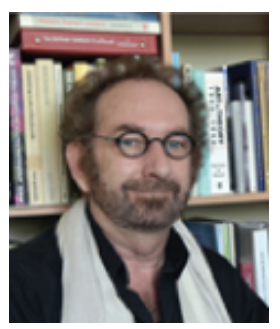

Dr. Hans Dieleman is of Dutch/Flemish origin, and holds a doctoral degree in sociology of knowledge from the Erasmus University Rotterdam, the Netherlands. He works as a full professor in the College of Sciences and Humanities of the Autonomous University of Mexico City (UACM), where he is currently the coordinator of the universities environmental program. He is an external professor in the National Mexican Polytechnic Institute (IPN) and a fellow of the Academy of Transdisciplinary Learning and Advanced Studies (ATLAS) in Texas, USA. Previously he worked in the Erasmus University Rotterdam in the Netherlands, was invited professor in the "Université Dauphine" in Paris, France and visiting professor in the Metropolitan University of Mexico City. He was a member of the academic team that prepared the Doctoral Program in Transdisciplinary Studies of the University of Veracruz in Jalapa, Mexico. His main research themes are sustainability, art and transdisciplinarity. Specific themes are epistemology, transdisciplinary hermeneutics, reflective practice, embodied cognition and education. The past 15 years he has been working on the development of the field of Art and Sustainability that allows him to integrate several of the above-mentioned themes.

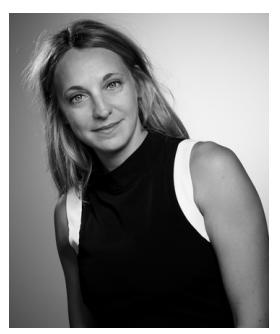

Francesca Cozzolino teaches humanities and social science at the École nationale supérieure des Arts Décoratifs (EnsAD), PSL Research University, Paris. She is a research associate at EnsadLab, the research laboratory in art and design at the EnsAD and an affiliate member at the Laboratoire d'Ethnologie et de Sociologie Comparative (LESC-CNRS) of the Paris Nanterre University.

Specialized in ethnography of artistic practices, her research intertwine visual studies and anthropology of art and writings with a special attention to writings displayed in public spaces. Since 2010, she has headed numerous inquiries worldwide into the field of art and design and has led several research missions in France and abroad (Europe, United-States, Benin and Mozambique). Her aim in these projects has been to develop a descriptive ontology of creation and by aiming at studying the different shapes and levels of creative agency, and its ability to operate within the social fabric.

She has published several book chapters and scientific papers and she often contributes to art and design journals and exhibition catalogues. She also collaborates with artists in implementing projects that combine both art and social science.

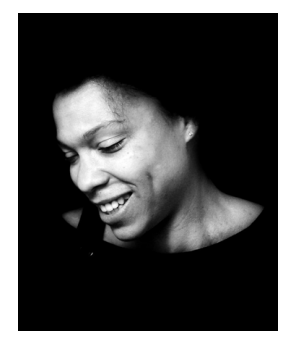

Anne Bationo Tillon is researcher in ergonomics (C3U/Paragraphe/ UniversitéParis 8). She contributes to transdisciplinarity projects since 15 years. Each research project is a new opportunity to enrich a "transitional approach". This theoretical approach combines instrumental approach (Rabardel, 1995) and the concept of intermediary area of experience (Winnicott, 1971). Her different research contributions aim to improve the understanding and better equip the subjects's intermediary area of experience in the fields of education activities, daily activities, work activities, and art activities. 